\title{
Milk prolactin response and quarter milk yield after experimental infection with coagulase-negative staphylococci in dairy heifers
}

\author{
K. Piccart, ${ }^{* 1}$ S. Piepers, ${ }^{*}$ J. Verbeke, ${ }^{*}$ N. M. de Sousa, $†$ J. F. Beckers, $†$ and S. De Vliegher* \\ *M-team and Mastitis and Milk Quality Research Unit, Department of Reproduction, Obstetrics and Herd Health, Faculty of Veterinary Medicine, \\ Ghent University, 9820 Merelbeke, Belgium \\ †Laboratory of Animal Endocrinology and Reproduction, Faculty of Veterinary Medicine, University of Liege, 4000 Liege, Belgium
}

\begin{abstract}
Coagulase-negative staphylococci (CNS) are the most common bacteria involved in subclinical mastitis in dairy cows. Remarkably, CNS-infected dairy heifers produce more milk than uninfected heifers. Because the lactation hormone prolactin (PRL) is also involved in mammary gland immunity, we investigated the milk PRL response and the mammary quarter milk yield following experimental CNS challenge. Eight healthy Holstein-Friesian heifers in mid-lactation were experimentally infected using a split-udder design with 3 different CNS strains: one Staphylococcus fleurettii (from sawdust bedding) and 2 Staphylococcus chromogenes strains (one isolate from a teat apex, the other isolate from a chronic intramammary infection). Three mammary quarters per heifer were simultaneously inoculated with $1.0 \times 10^{6} \mathrm{cfu}$, whereas the remaining mammary quarter was infused with sterile phosphate-buffered saline, serving as a control. An existing radioimmunoassay was modified, validated, and used to measure PRL frozen-thawed milk at various time points until $78 \mathrm{~h}$ after challenge. The mean milk PRL level tended to be higher in the CNS-challenged mammary quarters compared with the control mammary quarters (7.56 and $6.85 \mathrm{ng} / \mathrm{mL}$, respectively). The increase in PRL over time was significantly greater in the CNS-challenged mammary quarters than in the control mammary quarters. However, no difference was found in the PRL response when comparing each individual CNS strain with the control mammary quarters. The mean mammary quarter milk yield tended to be lower in the CNS-infected mammary quarters than in the control mammary quarters (1.73 and $1.98 \mathrm{~kg}$ per milking, respectively). The greatest milk loss occurred in the mammary quarters challenged with the intramammary strain of $S$. chromogenes. Future observational studies are needed to elucidate the relation between PRL, the
\end{abstract}

Received January 16, 2015.

Accepted April 5, 2015.

${ }^{1}$ Corresponding author: Kristine.Piccart@UGent.be milk yield, and the inflammatory condition, or infection status, of the mammary gland.

Key words: coagulase-negative staphylococci, dairy heifer, experimental mastitis, prolactin

\section{INTRODUCTION}

Bovine mastitis, an inflammation of the mammary gland, creates a huge economic burden on the global dairy industry (Bradley, 2002). Coagulase-negative staphylococci are the predominant group of bacteria involved in subclinical mastitis (Pyörälä and Taponen, 2009) and can cause clinical mastitis with mild symptoms (Taponen et al., 2006). Thus far, more than 10 species of CNS have been isolated from bovine milk (Piessens et al., 2011) with documented species-specific differences in putative virulence (Vanderhaeghen et al., 2014), ecology, and epidemiology (Vanderhaeghen et al., 2015). Contrary to what one might expect, various studies have observed a higher test-day milk yield in CNS-infected dairy heifers and multiparous cows compared with noninfected cows (Compton et al., 2007; Schukken et al., 2009; Piepers et al., 2010). Some studies have attributed a protective effect to pre-existing CNS IMI against IMI with more virulent mastitis pathogens (e.g., Piepers et al., 2010). A meta-analysis could not confirm this finding in observational studies, but nonetheless revealed a pronounced protective effect in challenge trials (Reyher et al., 2012). Still, the positive effect on milk yield could be an indirect result of the reduced incidence of clinical mastitis observed in CNS-infected animals (Piepers et al., 2010). Highproducing dairy cows might also be more susceptible to CNS IMI than low-yielding animals (Compton et al., 2007). However, even after correcting for these factors, an unexplained difference in milk yield of $2.0 \mathrm{~kg} / \mathrm{d}$ remained between CNS-infected and uninfected herd mates (Piepers et al., 2013), leaving the exact mechanism to be determined.

Prolactin (PRL) has been associated with over 300 different biological actions, including lactation and mammary gland development (Bole-Feysot et al., 
1998). In dairy cattle, PRL is required to initiate (Akers et al., 1981) and maintain the milk production after parturition (Lacasse et al., 2012). The protein hormone also acts as a cytokine on molecular and functional levels (Goffin et al., 2002). The ubiquitous PRL receptor belongs to the class I cytokine receptor superfamily, which also includes the receptors of several interleukins and hematopoietic growth factors (Bazan, 1989, 1990). The hormone promotes the activity of macrophages (Edwards et al., 1987), inhibits the apoptosis of T-lymphocytes caused by glucocorticoids (Krishnan et al., 2003), and stimulates the production of tumor necrosis factor- $\alpha$ and IL-12 (Brand et al., 2004). Considering the immunomodulatory actions of PRL, several studies have focused on its potential involvement in bovine mastitis. The periparturient PRL peak coincides with the principal risk period for developing mastitis (Burton et al., 2001). The hormone induces the in vitro synthesis of several cytokines in bovine mammary epithelial cells through the activation of nuclear factor kappa B (Boutet et al., 2007). Although the circulating PRL level is not affected by acute, clinical mastitis (Hockett et al., 2000; Vanselow et al., 2006), a positive correlation was found between SCC and PRL concentration in milk of chronically infected mammary quarters (Boutet et al., 2007).

Because PRL is recognized as a pro-inflammatory cytokine, we hypothesize that milk PRL increases in response to an IMI with CNS. Furthermore, we hypothesize that the quarter milk yield (QMY) also increases after CNS IMI, assuming PRL stimulates the production of milk. To investigate this, an experimental challenge trial was set up using 8 clinically healthy, midlactating dairy heifers using 3 different CNS strains. An existing radioimmunoassay for fresh milk was modified and subsequently validated to measure bovine PRL in frozen-thawed milk samples. To assess the epithelial integrity of the blood-milk barrier, the sodium, potassium, and chloride levels were also determined in milk.

\section{MATERIALS AND METHODS}

The study is in compliance with the European Directive 2010/63/EU and was approved by the ethical committee of the Faculty of Veterinary Medicine, Ghent University (EC2012/73).

\section{Animals}

The study took place between December 2012 and May 2013 at the research dairy farm of Ghent University (Biocentrum Agri-Vet, Melle, Belgium). Eight clinically healthy Holstein-Friesian heifers in mid-lactation (78278 DIM) were selected. Heifers with a known history of clinical mastitis or persistent high SCC $(>150,000$ cells $/ \mathrm{mL}$ ) were excluded from the trial. Milk samples were cultured according to NMC guidelines 48 and 24 $\mathrm{h}$ before inoculation to ensure all mammary quarters were free from IMI (NMC, 1999).

\section{CNS Strains}

All heifers were inoculated with 2 different wild strains of Staphylococcus chromogenes and 1 Staphylococcus fleurettii strain. The $S$. fleurettii isolate was recovered from sawdust bedding in a dairy barn (Piessens et al., 2011; Breyne et al., 2015). The first S. chromogenes strain originated from a cow suffering from a persistent IMI (hereafter referred to as S. chromogenes IM; Supré et al., 2011; Breyne et al., 2015), whereas the second $S$. chromogenes isolate was cultured from the teat apex of a heifer (hereafter referred to as $S$. chromogenes TA; De Vliegher et al., 2004; Breyne et al., 2015). The S. chromogenes TA strain has the ability to inhibit the growth of several major pathogens under laboratory conditions (De Vliegher et al., 2004), whereas the S. chromogenes IM strain does not. The 2 strains also elicit a different immune response in mice (Breyne et al., 2015), and the TA strain is unable to grow in anaerobic iron-depleted medium unlike the IM strain (unpublished data). An inoculum of $1.0 \times 10^{6} \mathrm{cfu}$ of each strain was prepared to induce an experimental infection. The live number of cfu was determined by plating serial dilutions of the bacterial stock on tryptic soy agar.

\section{Experimental Study Design}

A split-udder design was used. The concept of the split-udder model is grounded on within-heifer comparisons to reduce individual variation (Sipka et al., 2014). Following the morning milking, 3 mammary quarters of each heifer were instantaneously inoculated with the 3 aforementioned CNS strains (one per mammary quarter) diluted in $5 \mathrm{~mL}$ of PBS using a sterile catheter (Vygon, Ecouen, France). The fourth mammary quarter, serving as a control, was infused in the same manner with $5 \mathrm{~mL}$ of sterile, pyrogen-free PBS. Milk samples for PRL analysis and microbiological culturing were collected from each mammary quarter at $0,4,6,9,12,18,24,28,32,36,48,54,60,72$, and 78 $\mathrm{h}$ postinoculation (PI). Milk samples for ion analysis were collected at 0,24 , and $48 \mathrm{~h}$ PI. The milk SCC was determined using a DeLaval Cell Counter (DeLaval, Tumba, Sweden). Bacteriological culturing was performed according to NMC guidelines (NMC, 1999). The milk samples for the PRL and ion analysis were stored at $-20^{\circ} \mathrm{C}$. The cows were milked twice a day with $12-\mathrm{h}$ intervals, and QMY was registered using a mammary 
quarter milking device. The cow were examined clinically at each sampling. Rectal temperature, heart rate, respiration rate, rumen motility, fecal consistency, and milk appearance were registered.

\section{Milk Analysis}

Prolactin RIA. Milk PRL was determined by a double antibody, homologous RIA adapted from Malven and McMurtry (1974). Because this protocol was developed for fresh, whole milk, we first modified and validated the RIA for frozen milk samples in particular. For the validation, mammary quarter milk samples (n $=4$ ) were collected from randomly selected, multiparous Holstein-Friesian cows at a Belgian commercial dairy farm. The samples were then stored at $-20^{\circ} \mathrm{C}$ for $96 \mathrm{~h}$. Afterward, the milk samples were thawed in a warm water bath at $40^{\circ} \mathrm{C}$ for 30 min (Chew et al., 1977) and centrifuged at $1,800 \times g$ for $15 \mathrm{~min}$ at $20^{\circ} \mathrm{C}$ (Sigma 2-16K, Sigma Laborzentrifugen $\mathrm{GmbH}$, Osterode am Harz, Germany). Bovine PRL (NIH-B5) was used both as a standard and tracer. To generate the tracer, bovine PRL was radiolabeled with ${ }^{125} \mathrm{I}$ using the lactoperoxidase technique (Thorell and Johansson, 1971). A standard curve ranging from 0.8 to $100 \mathrm{ng} /$ $\mathrm{mL}$ was prepared in Tris buffer $(25 \mathrm{~m} M$ Tris; $0.01 \mathrm{mM}$ $\mathrm{MgCl}_{2} ; 1.5 \mathrm{mM} \mathrm{NaN}_{3}$ ) containing $0.1 \%$ (wt/vol) BSA at $\mathrm{pH}$ 7.5. To analyze each standard concentration, 100 $\mu \mathrm{L}$ was added to duplicate tubes containing $200 \mu \mathrm{L}$ of Tris-BSA buffer. A sample volume of $50 \mu \mathrm{L}$ was used for milk to minimize potential incubation damage to the labeled antigen (Malven and McMurtry, 1974). Afterward, $100 \mu \mathrm{L}$ of tracer of approximately $30,000 \mathrm{cpm}$ was added, followed by $100 \mu \mathrm{L}$ of antiserum (R\#144). This antiserum was collected from a rabbit after injection with biological bovine PRL (NIH-B5; Boutet et al., 2007). An antibody titer of 1:120,000 was previously selected for this assay, resulting in the binding of circa 30 to $40 \%$ of the total amount of ${ }^{125} \mathrm{I}$-PRL. The amount of radiolabelled bPRL bound to the antiserum in tubes containing no bPRL $\left(\mathrm{B}_{0}\right)$ was designated as $100 \%{ }^{125} \mathrm{I}$ bound. After an overnight incubation at room temperature, the antibody-bound fraction of PRL was precipitated using a secondary antibody polyethylene glycol solution (Ayad et al., 2007). The radioactivity of the precipitated ${ }^{125} \mathrm{I}-\mathrm{PRL}$ was measured with a gamma counter (LKB Wallac 1261 Multigamma automatic counter, Breda, the Netherlands).

Five parameters were taken into account to validate the RIA: (1) inter- and intraassay coefficient of variation, (2) minimal detection limit (MDL), (3) parallelism, (4) accuracy, and (5) specificity. Three milk samples with a low $(2.4 \mathrm{ng} / \mathrm{mL})$, medium $(12.9 \mathrm{ng} / \mathrm{mL})$, and high $(19.7 \mathrm{ng} / \mathrm{mL})$ PRL concentration were used to calculate the inter- and intraassay coefficient of variation. To assess the intraassay coefficient of variation, the samples were assayed 10 times within the same run. The interassay coefficient of variation was evaluated by measuring each sample in 10 consecutive assays. The MDL was calculated by measuring the mean concentration of $20 \mathrm{~B}_{0}$ (zero standard) replicates minus twice the standard deviation within the same assay. For the evaluation of parallelism, a sample dilution curve of a frozen-thawed sample was generated to detect any potential interference of the sample matrix. The accuracy or spike-recovery of the assay was studied by adding a series of known amounts of PRL to a sample with a low endogenous PRL concentration. To evaluate potential cross-reactivity (specificity), 2 structurally similar compounds were tested: native ovine growth hormone (oGH) and bovine placental lactogen (bPL). The validated RIA was then applied to all mammary quarter milk samples from the 8 heifers in the present experimental trial.

Indicators of Epithelial Integrity. The milk samples were thawed and subsequently centrifuged at $16,000 \times g$ for $30 \mathrm{~min}$ at $4^{\circ} \mathrm{C}$. The sodium, potassium, and chloride concentrations were analyzed in the fatdepleted fraction using an ion-selective electrode analyzer (Roche, Basel, Switzerland).

\section{Statistical Analyses}

The response of mammary quarter milk PRL after CNS challenge was evaluated using a linear mixed regression model (SPSS 22.0, Chicago, IL), with the time of sampling, quadratic term of time of sampling, and inoculum as predictor variables. Time of sampling and its quadratic term were included as a continuous variable, whereas inoculum was considered as a categorical variable. The interaction between inoculum and time of sampling was also tested, but only kept in the model when significant. A similar model was constructed to assess the association between QMY, and time of sampling, its quadratic term, and inoculum as predictor variables. For both outcome variables, the inoculum was initially considered a dichotomous variable (challenged versus control). In a second approach, the effect of all different CNS strains was examined (S. chromogenes IM, S. chromogenes TA, and S. fleurettii). To determine the relationship between inoculation (challenge versus control) and the milk ion concentration, comparable linear mixed regression models were constructed for sodium, potassium, and chloride. Sampling time was included as a 3-level categorical variable $(0,24$, and 48 h). A natural logarithmic transformation of sodium and chloride was performed to obtain a normalized distribution of the residuals. In all aforementioned analyses, 
heifer and mammary quarter were included as random effects to account for the correlated nature of the data. Compound symmetry was selected as a covariance pattern to account for the clustering of repeated samplings within mammary quarter. Statistical significance was set at $P \leq 0.05$.

\section{RESULTS}

\section{Experimental Infection}

The data of one mammary quarter were omitted from the analysis due to a naturally occurring IMI. Another mammary quarter was also excluded from the analysis for the same reason, but only $12 \mathrm{~h}$ after inoculation. An increase in SCC was observed in all challenged mammary quarters, indicating the establishment of IMI, whereas the SCC in the control mammary quarters remained low [geometric mean of 47,000 cells/ $\mathrm{mL}$; interquartile range (IQR) of 31,000-71,000 cells/ $\mathrm{mL}$. Twenty-four hours PI, the S. fleurettii, S. chromogenes TA, and $S$. chromogenes IM challenged mammary quarters had a geometric mean SCC of 2,400,000 cells/ mL (IQR: 442,000-3,420,000 cells/mL), 669,000 cells/ $\mathrm{mL}$ (IQR: 441,000-1,681,000 cells/mL), and 2,596,000 cells/mL (IQR: 1,662,000-4,775,000 cells/mL), respectively. The challenged mammary quarters did not show any visual signs of clinical mastitis. However, 3 heifers did experience a short bout of fever $\left(>39.5^{\circ} \mathrm{C}\right)$ between 9 and $12 \mathrm{~h}$ PI. The S. chromogenes IM and TA strains were recovered from milk up to $78 \mathrm{~h}$ PI. In all mammary quarters, the $S$. fleurettii strain was eliminated within $9 \mathrm{~h}$ PI. No pathogens other than CNS were isolated during the study. The PBS-infused mammary quarters remained free from infection during the entire study period as demonstrated by bacteriological culture.

\section{Prolactin}

RIA Validation. The intraassay coefficient of variation for samples with a low, medium, and high PRL concentration was $9.7,8.3$, and $8.1 \%$, respectively. The interassay coefficient of variation for the corresponding samples was $11.9,14.4$, and $16.1 \%$, respectively. The MDL of the assay was $0.536 \mathrm{ng} / \mathrm{mL}$. Serial dilutions showed a dose-response curve parallel to the standard curve (data not shown). The recovery ratio of the spiked PRL was consistently $>85 \%$. The binding of radiolabelled PRL remained unaltered when testing the cross-reactivity, except for very high concentrations of oGH (starting at $6.2 \times 10^{3} \mathrm{ng} / \mathrm{mL}$ ). This slightly interfered with the assay $\left(\mathrm{B} / \mathrm{B}_{0}<0.80\right)$, resulting in an apparent increase of the PRL concentration.
Milk PRL. The overall mean PRL concentration tended to be higher in the challenged mammary quarters than in the control mammary quarters (LSM = 7.56 and $6.85 \mathrm{ng} / \mathrm{mL}$, respectively) throughout the study $(P=0.10$, Table 1$)$. The PRL level varied over time in both challenged and control mammary quarters, although not in a linear manner $(P<0.001)$. The evolution of PRL over time was different between the challenged and the control mammary quarters (interaction inoculum $\times$ time of sampling: $P=0.05$, Figure 1). No significant difference was observed in the PRL response between each of the 3 CNS strains and the control mammary quarters $(P=0.77)$, nor in the evolution over time between strains (interaction inoculum $\times$ time of sampling: $P=0.14$ ).

\section{Quarter Milk Yield}

The overall mean QMY per milking tended to be lower in the CNS challenged mammary quarters than in the control mammary quarters (LSM $=1.73$ and 1.98 $\mathrm{kg}$, respectively) throughout the study $(P=0.06$, Table $2 \mathrm{a})$. The decline of the QMY over time was greater in the CNS-challenged mammary quarters than in the control mammary quarters (interaction inoculum $\times$ time of sampling: $P<0.001$, Figure 2). The difference in QMY compared with the control mammary quarters was more pronounced in the mammary quarters challenged with $S$. chromogenes IM ( $-0.38 \mathrm{~kg}$ per milking) than with $S$. chromogenes TA $(-0.21 \mathrm{~kg}$ per milking) or S. fleurettii ( $-0.17 \mathrm{~kg}$ per milking; Table 2$)$.

\section{Blood-Milk Barrier}

The concentration of potassium in milk was not significantly influenced by the challenge with CNS strains $(P=0.37)$. A small, but significant increase in the natural logarithmic of sodium and chloride was noted in the challenged quarters (interaction inoculum $\times$ time of sampling $P<0.05$ ). However, the sodium and chloride levels did not exceed the upper limit of the normal reference ranges (Figure 3; Gaucheron, 2005).

\section{DISCUSSION}

Because CNS-infected cows appear to produce more milk than noninfected cows (Compton et al., 2007; Schukken et al., 2009; Piepers et al., 2010), we investigated the milk yield and the response of milk PRL after CNS challenge in clinically healthy dairy heifers. A plethora of evidence implicates PRL as an immunomodulating factor (Edwards et al., 1987; Krishnan et al., 2003; Brand et al., 2004; Boutet et al., 2007). 


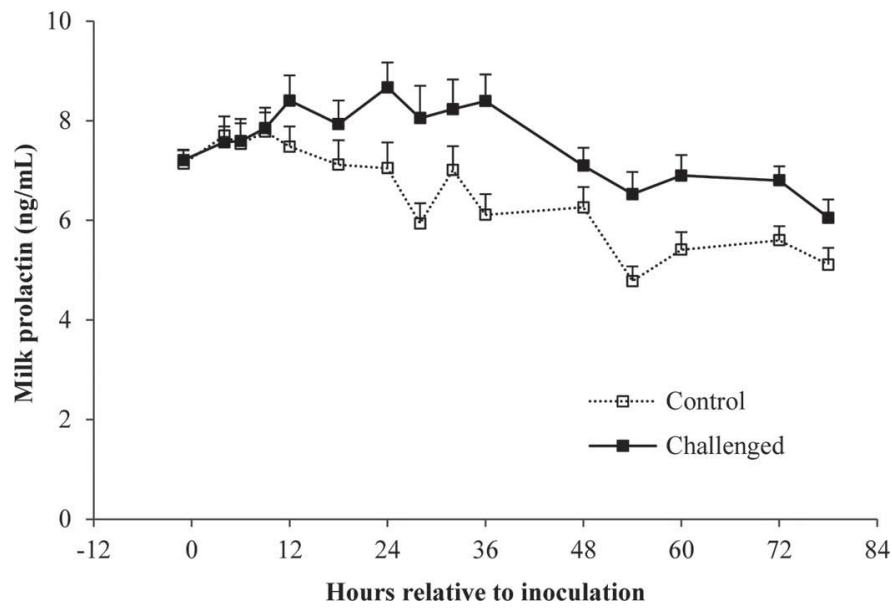

Figure 1. The average prolactin (PRL; \pm SEM) concentration in milk following experimental inoculation in challenged quarters versus control quarters. The challenged quarters were inoculated with Staphylococcus fleurettii, the teat apex strain of Staphylococcus chromogenes, and the intramammary strain of Staphylococcus chromogenes.

Therefore, we hypothesized that PRL increases in the milk after CNS infection. Milk PRL might then simultaneously stimulate the secretion of milk as a galactopoietic hormone (Lacasse et al., 2012) in a paracrine or autocrine manner (Clevenger et al., 1995), potentially explaining the aforementioned milk yield increase in CNS-infected cows.

First, the modified PRL RIA for frozen-thawed milk samples proved to be reproducible, accurate, and specific. Only high concentrations of GH interfere with the assay, resulting in an apparent increase of PRL. This might be due either to cross-specificity or to the pres- ence of trace amounts of pituitary PRL in the native GH preparation. Either way, any cross-reactivity is irrelevant because the endogenous GH amount is limited in bovine milk (Burton et al., 1994).

This study confirmed that milk PRL indeed increases in challenged mammary quarters compared with control mammary quarters after CNS inoculation. This corresponds with the results from Boutet et al. (2007), demonstrating that the PRL level is elevated in chronically infected mammary quarters with high SCC (Boutet et al., 2007). Even though others have observed an increased milk production in naturally CNS-infected cows (Schukken et al., 2009; Piepers et al., 2013), this study reported a substantial milk loss in both challenged and control mammary quarters. Then again, this observation is not entirely unexpected. Unlike the previous observational studies, our experimental trial only monitored the milk yield for a short period of time during the acute phase of inflammation. This experimental challenge might not necessarily reflect a natural infection, based on the high infection dose and the direct intracisternal inoculation of CNS. Also, the aforementioned observational studies (Schukken et al., 2009; Piepers et al., 2013) focused on milk production at animal level, where uninfected glands could compensate for the production loss in CNS-infected mammary quarters (Leitner et al., 2004). Our study measured the production at the mammary quarter level and found transitory milk loss in all mammary quarters. The extent of production loss in the unchallenged mammary quarters has previously been used to score the severity of experimental mastitis (Burvenich et al., 2003). Because the production of the control mammary

Table 1. Linear mixed regression model for milk prolactin after experimental infection, including all 3 CNS strains combined (model 1; left) and with Staphylococcus chromogenes $\mathrm{TA}^{1}$, S. chromogenes $\mathrm{IM}^{2}$, and S. fleurettii considered separately (model 2; right)

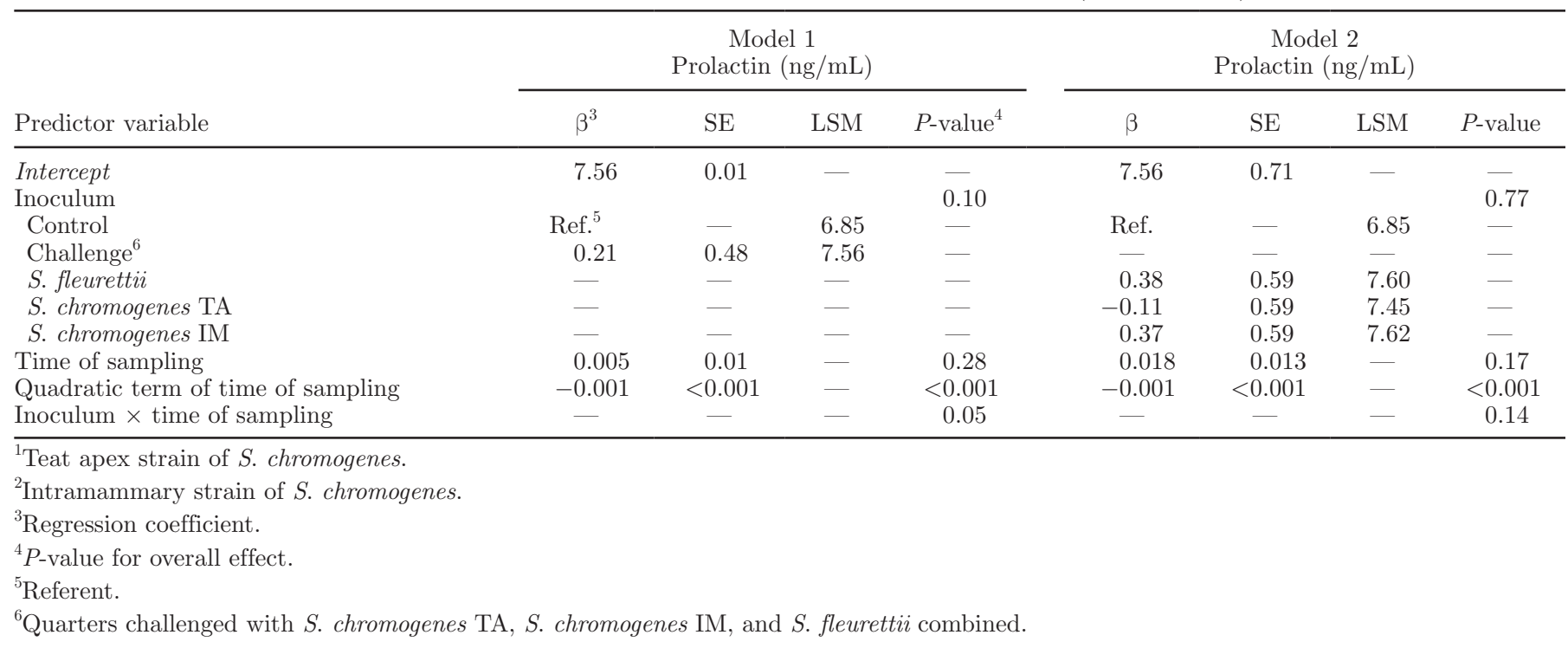


Table 2. Linear mixed regression model for quarter milk yield after experimental infection, including all 3 CNS strains combined (model 1; left) and with Staphylococcus chromogenes $\mathrm{TA}^{1}$, S. chromogenes $\mathrm{IM}^{2}$, and S. fleurettii considered separately (model 2; right)

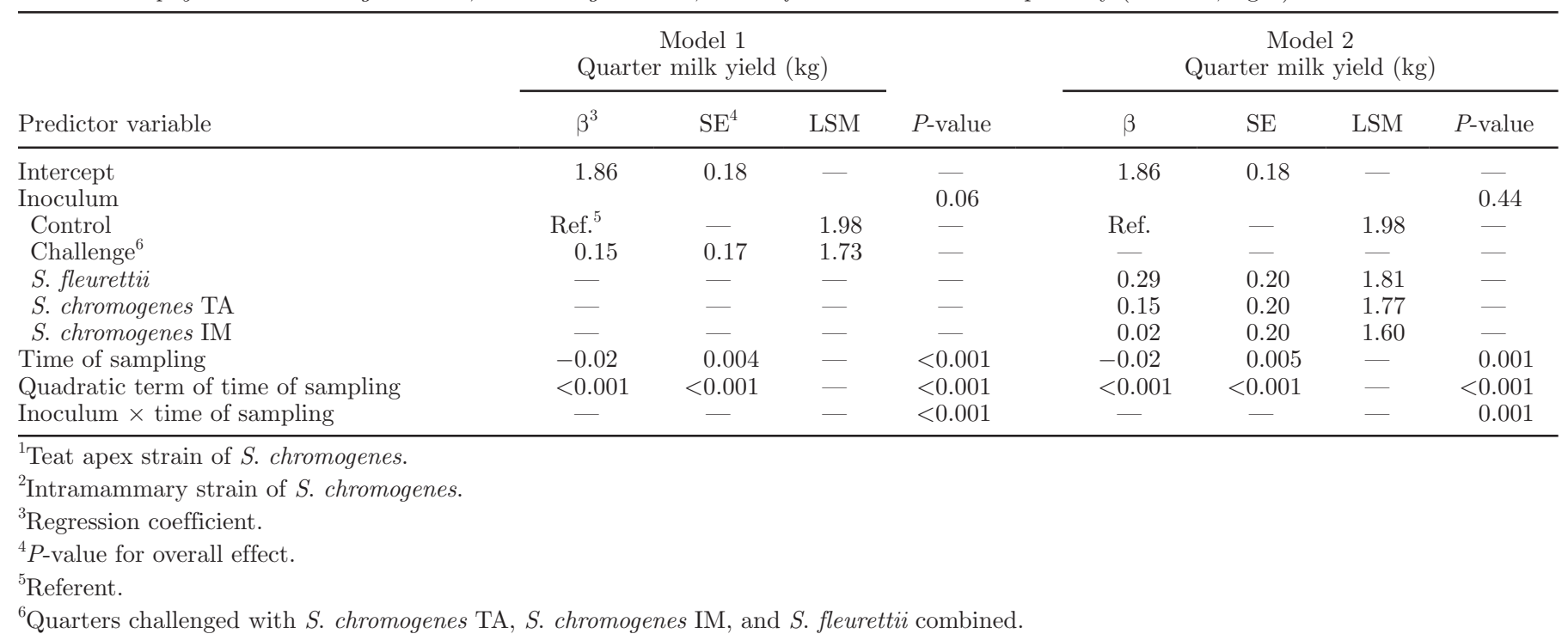

quarters was practically restored in all cows after $48 \mathrm{~h}$, we conclude that the systemic and long-term effects of the induced CNS IMI, even when using a high inoculum dose, were limited. As seen in other experimental infection trials, the CNS in this study evoke a mild inflammatory response despite the high infectious dose (Simojoki et al., 2009, 2011). It should, however, be noted that the overall milk yield during the experimental trial was unexpectedly low in all mammary quarters for Holstein-Friesian heifers. We believe this could be

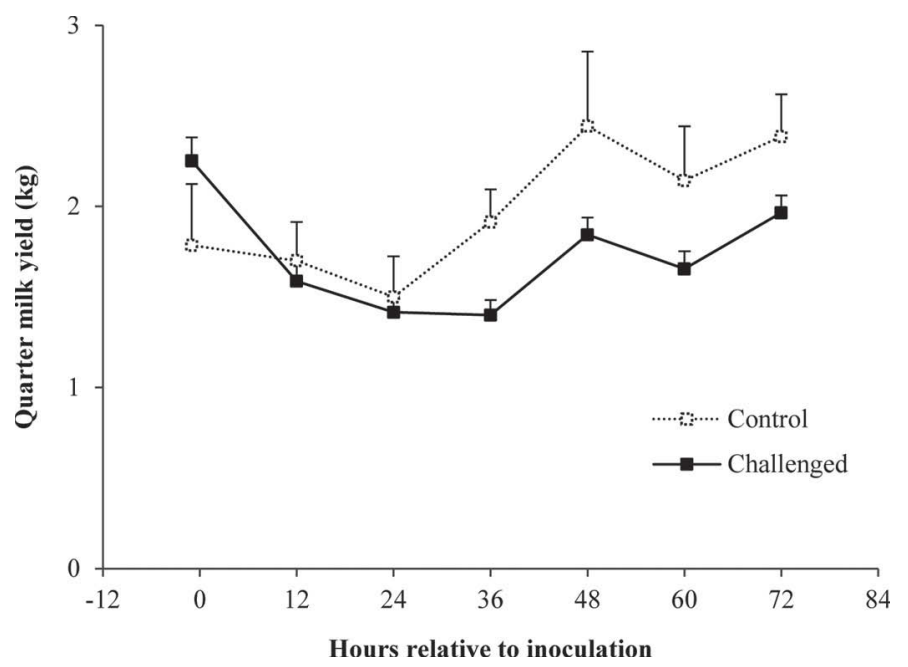

Figure 2. Mean quarter milk yield ( \pm SEM) following experimental inoculation in challenged quarters versus control quarters. The challenged quarters were inoculated with Staphylococcus fleurettii, the teat apex strain of Staphylococcus chromogenes, and the intramammary strain of Staphylococcus chromogenes. related to the different housing conditions and milking routines during the experimental trial.

Under physiological conditions, circulating pituitary PRL is transported from the bloodstream to the milk compartment via transcytosis. After binding on the membrane receptor, PRL is internalized by the mammary epithelial cell and subsequently released into the milk through secretory vesicles (Ollivier-Bousquet, 1998). Mastitis increases tight junction permeability, hereby enabling the paracellular transport of bloodborne components (Nguyen and Neville, 1998). Changes in milk ion concentration can indicate the disruption of the blood-milk barrier (Stelwagen et al., 1994). In this study, the sodium and chloride levels increased significantly in the challenged mammary quarters. This might imply that the PRL merely leaks from the bloodstream into the milk compartment, as a result of an increased tight junction permeability. Whether the milk PRL increase is entirely due to passive diffusion can neither be confirmed nor denied in this experimental setup. The biological significance of plasma-borne proteins in the milk could be questioned. Future research should address the origin of PRL in milk. Other ruminants, such as sheep and goats (Le Provost et al., 1994), are able to produce extra-pituitary PRL in the mammary gland. So far, this has never been demonstrated in cattle, but it would support the hypothesis of PRL as a pro-inflammatory cytokine and autocrine lactation hormone. Although Boutet et al. (2007) found no association between bacterial species and PRL concentration, we also wonder if the release of PRL during IMI is pathogen dependent. Additional longitudinal studies on mammary quarter level will shed more light on the 
a)

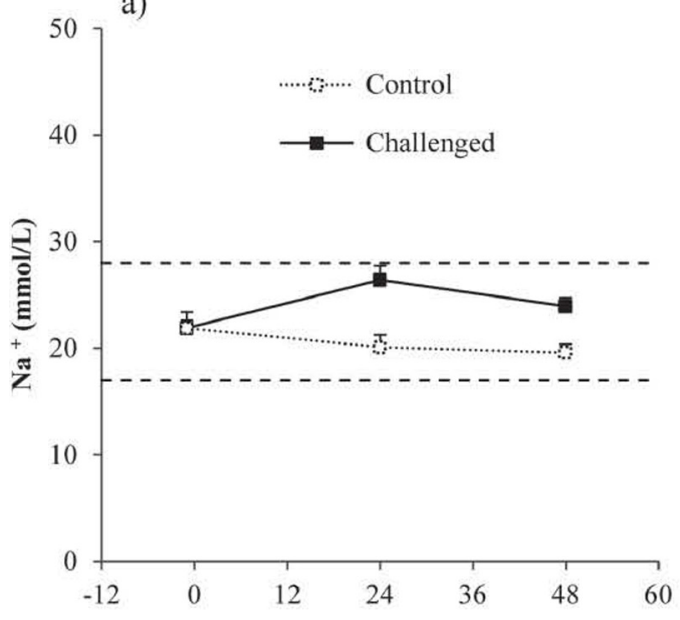

b)

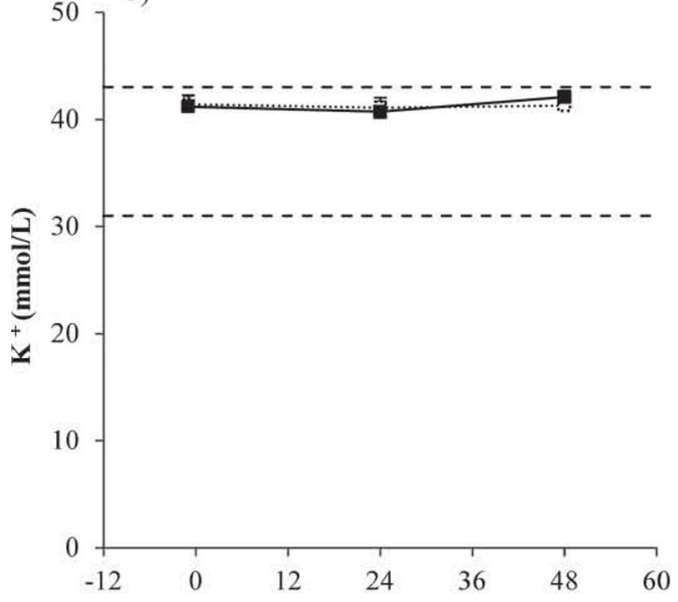

c)

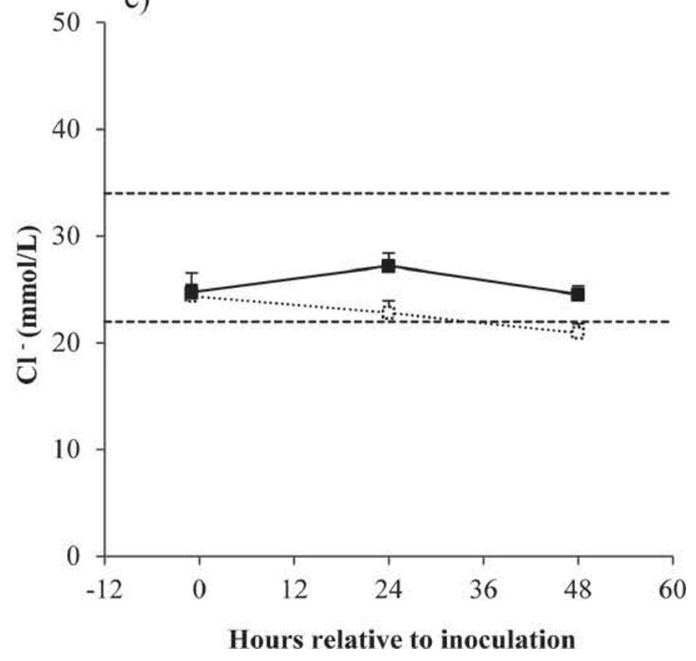

Figure 3. The average $( \pm \mathrm{SEM})$ milk $\mathrm{Na}^{+}, \mathrm{K}^{+}$, and $\mathrm{Cl}^{-}$levels in the control and challenged quarters. The dashed horizontal lines represent the upper and lower reference range of the respective ions in bovine milk from noninfected mammary glands. The challenged quarters were inoculated with Staphylococcus fleurettii, the teat apex strain of Staphylococcus chromogenes and the intramammary strain of Staphylococcus chromogenes. true association between QMY and CNS infections, and clarify the role of PRL in IMI.

\section{CONCLUSIONS}

This study demonstrated that milk PRL increases after an experimental intramammary CNS challenge in dairy heifers. The mechanism behind this PRL response and its biological relevance remain to be determined.

\section{ACKNOWLEDGMENTS}

We thank A. F. Parlow of the National Hormone and Peptide Program for kindly providing the bovine prolactin, as well as Aline Flora Tchimbou (University of Liege) and Lars Hulpio (Ghent University) for their excellent technical assistance.

\section{REFERENCES}

Akers, R. M., D. E. Bauman, A. V. Capuco, G. T. Goodman, and H. A. Tucker. 1981. Prolactin regulation of milk secretion and biochemical differentiation of mammary epithelial-cells in periparturient cows. Endocrinology 109:23-30.

Ayad, A., N. M. Sousa, J. Sulon, L. Hornick, J. Watts, F. Lopez-Gatius, M. Iguer-Ouada, and J. F. Beckers. 2007. Influence of progesterone concentrations on secretory functions of throphoblast and pituitary during the first trimester of pregnancy in dairy cattle. Theriogenology 67:1503-1511.

Bazan, J. F. 1989. A novel family of growth-factor receptors-A common binding domain in the growth-hormone, prolactin, erythropoietin and $\mathrm{Il}-6$ receptors, and the $\mathrm{P} 75 \mathrm{Il}-2$ receptor beta-chain. Biochem. Biophys. Res. Commun. 164:788-795.

Bazan, J. F. 1990. Structural design and molecular evolution of a cytokine receptor superfamily. Proc. Natl. Acad. Sci. USA 87:69346938.

Bole-Feysot, C., V. Goffin, M. Edery, N. Binart, and P. A. Kelly. 1998. Prolactin (PRL) and its receptor: Actions, signal transduction pathways and phenotypes observed in PRL receptor knockout mice. Endocr. Rev. 19:225-268.

Boutet, P., J. Sulon, R. Closset, J. Detilleux, J. F. Beckers, F. Bureau, and P. Lekeux. 2007. Prolactin-induced activation of nuclear factor kappa B in bovine mammary epithelial cells: Role in chronic mastitis. J. Dairy Sci. 90:155-164.

Bradley, A. J. 2002. Bovine mastitis: An evolving disease. Vet. J. 164:116-128.

Brand, J. M., C. Frohn, K. Cziupka, C. Brockmann, H. Kirchner, and J. Luhm. 2004. Prolactin triggers pro-inflammatory immune responses in peripheral immune cells. Eur. Cytokine Netw. 15:99104.

Breyne, K., S. De Vliegher, A. De Visscher, S. Piepers, and E. Meyer. 2015. A pilot study using a mouse mastitis model to study the differences between bovine associated coagulase-negative staphylococci. J. Dairy Sci. 98:1090-1100.

Burton, J. L., S. A. Madsen, J. Yao, S. S. Sipkovsky, and P. M. Coussens. 2001. An immunogenomics approach to understanding periparturient immunosuppression and mastitis susceptibility in dairy cows. Acta Vet. Scand. 42:407-424.

Burton, J. L., B. W. Mcbride, E. Block, D. R. Glimm, and J. J. Kennelly. 1994. A review of bovine growth hormone. Can. J. Anim. Sci. $74: 167-201$.

Burvenich, C., V. Van Merris, J. Mehrzad, A. Diez-Fraile, and L. Duchateau. 2003. Severity of E. coli mastitis is mainly determined by cow factors. Vet. Res. 34:521-564.

Journal of Dairy Science Vol. 98 No. 7, 2015 
Chew, B. P., R. E. Erb, and P. V. Malven. 1977. Assay of prolactin after freezing cow's milk. J. Dairy Sci. 60:981-984.

Clevenger, C. V., W. P. Chang, W. Ngo, T. L. Pasha, K. T. Montone, and J. E. Tomaszewski. 1995. Expression of prolactin and prolactin receptor in human breast carcinoma. Evidence for an autocrine/paracrine loop. Am. J. Pathol. 146:695-705.

Compton, C. W. R., C. Heuer, K. Parker, and S. McDougall. 2007. Epidemiology of mastitis in pasture-grazed peripartum dairy heifers and its effects on productivity. J. Dairy Sci. 90:4157-4170.

De Vliegher, S., G. Opsomer, A. Vanrolleghem, L. A. Devriese, O. C Sampimon, J. Sol, H. W. Barkema, F. Haesebrouck, and A. de Kruif. 2004. In vitro growth inhibition of major mastitis pathogens by Staphylococcus chromogenes originating from teat apices of dairy heifers. Vet. Microbiol. 101:215-221.

Edwards, C. K., J. M. Schepper, L. M. Yunger, and K. W. Kelley. 1987. Somatotropin and prolactin enhance respiratory burst activity of macrophages. Ann. N. Y. Acad. Sci. 540:698-699.

Gaucheron, F. 2005. The minerals of milk. Reprod. Nutr. Dev. 45:473-483.

Goffin, V., N. Binart, P. Touraine, and P. A. Kelly. 2002. Prolactin: The new biology of an old hormone. Annu. Rev. Physiol. 64:47-67.

Hockett, M. E., F. M. Hopkins, M. J. Lewis, A. M. Saxton, H. H. Dowlen, S. P. Oliver, and F. N. Schrick. 2000. Endocrine profiles of dairy cows following experimentally induced clinical mastitis during early lactation. Anim. Reprod. Sci. 58:241-251.

Krishnan, N., O. Thellin, D. J. Buckley, N. D. Horseman, and A. R. Buckley. 2003. Prolactin suppresses glucocorticoid-induced thymocyte apoptosis in vivo. Endocrinology 144:2102-2110.

Lacasse, P., V. Lollivier, F. Dessauge, R. M. Bruckmaier, S. Ollier and M. Boutinaud. 2012. New developments on the galactopoietic role of prolactin in dairy ruminants. Domest. Anim. Endocrinol. 43:154-160.

Le Provost, F., C. Leroux, P. Martin, P. Gaye, and J. Dijane. 1994 Prolactin gene expression in ovine and caprine mammary gland. Neuroendocrinology 60:305-313.

Malven, P. V., and J. McMurtry. 1974. Measurement of prolactin in milk by radioimmunoassay. J. Dairy Sci. 57:411-415.

Leitner, G., U. Merin, and N. Silanikove. 2004. Changes in milk composition as affected by subclinical mastitis in goats. J. Dairy Sci. $87: 1719-1726$

National Mastitis Council. 1999. Laboratory Handbook on Bovine Mastitis. National Mastitis Counc. Inc., Madison, WI.

Nguyen, D. A., and M. C. Neville. 1998. Tight junction regulation in the mammary gland. J. Mammary Gland Biol. Neoplasia 3:233246.

Ollivier-Bousquet, M. 1998. Transferrin and prolactin transcytosis in the lactating mammary epithelial cell. J. Mammary Gland Biol. Neoplasia 3:303-313.

Piepers, S., G. Opsomer, H. W. Barkema, A. de Kruif, and S. De Vliegher. 2010. Heifers infected with coagulase-negative staphylococci in early lactation have fewer cases of clinical mastitis and higher milk production in their first lactation than noninfected heifers. J. Dairy Sci. 93:2014-2024.

Piepers, S., Y. H. Schukken, P. Passchyn, and S. De Vliegher. 2013. The effect of intramammary infection with coagulase-negative staphylococci in early lactating heifers on milk yield throughout first lactation revisited. J. Dairy Sci. 96:5095-5105.
Piessens, V., E. Van Coillie, B. Verbist, K. Supré, G. Braem, A. Van Nuffel, L. De Vuyst, M. Heyndrickx, and S. De Vliegher. 2011. Distribution of coagulase-negative Staphylococcus species from milk and environment of dairy cows differs between herds. J. Dairy Sci. 94:2933-2944.

Pyörälä, S., and S. Taponen. 2009. Coagulase-negative staphylococciEmerging mastitis pathogens. Vet. Microbiol. 134:3-8.

Reyher, K. K., D. Haine, I. R. Dohoo, and C. W. Revie. 2012. Examining the effect of intramammary infections with minor mastitis pathogens on the acquisition of new intramammary infections with major mastitis pathogens-A systematic review and meta-analysis. J. Dairy Sci. 95:6483-6502.

Schukken, Y. H., R. N. Gonzalez, L. L. Tikofsky, H. F. Schulte, C. G. Santisteban, F. L. Welcome, G. J. Bennett, M. J. Zurakowski, and R. N. Zadoks. 2009. CNS mastitis: Nothing to worry about? Vet. Microbiol. 134:9-14.

Simojoki, H., T. Orro, S. Taponen, and S. Pyörälä. 2009. Host response in bovine mastitis experimentally induced with Staphylococcus chromogenes. Vet. Microbiol. 134:95-99.

Simojoki, H., T. Salomäki, S. Taponen, A. Iivanainen, and S. Pyörälä. 2011. Innate immune response in experimentally induced bovine intramammary infection with Staphylococcus simulans and S. epidermidis. Vet. Res. 42:49.

Sipka, A., S. Klaessig, G. E. Duhamel, J. Swinkels, P. Rainard, and Y. Schukken. 2014. Impact of intramammary treatment on gene expression profiles in bovine Escherichia coli mastitis. PLoS ONE 9:e85579.

Stelwagen, K., S. R. Davis, V. C. Farr, C. G. Prosser, and C. G. an Sherlock. 1994. Mammary epithelial cell tight junction integrity and mammary blood flow during an extended milking interval in goats. J. Dairy Sci. 77:426-432.

Supré, K., F. Haesebrouck, R. N. Zadoks, M. Vaneechoutte, S. Piepers, and S. De Vliegher. 2011. Some coagulase-negative Staphylococcus species affect udder health more than others. J. Dairy Sci. 94:2329-2340.

Taponen, S., H. Simojoki, M. Haveri, H. D. Larsen, and S. Pyörälä. 2006. Clinical characteristics and persistence of bovine mastitis caused by different species of coagulase-negative staphylococci identified with API or AFLP. Vet. Microbiol. 115:199-207.

Thorell, J. I., and B. Johansson. 1971. Enzymatic iodination of polypeptides with I-125 to high specific activity. Biochim. Biophys. Acta 251:363-369.

Vanderhaeghen, W., S. Piepers, F. Leroy, E. Van Coillie, F. Haesebrouck, and S. De Vliegher. 2014. Invited review: Effect, persistence, and virulence of coagulase-negative Staphylococcus species associated with ruminant udder health. J. Dairy Sci. 97:5275-5293.

Vanderhaeghen, W., S. Piepers, F. Leroy, E. Van Coillie, F. Haesebrouck, and S. De Vliegher. 2015. Identification, typing and ecology of coagulase-negative staphylococci associated with ruminants. Vet. J. 203:44-51.

Vanselow, J., W. Yang, J. Herrmann, H. Zerbe, H. J. Schuberth, W. Petzl, W. Tomek, and H. M. Seyfert. 2006. DNA-remethylation around a STAT5-binding enhancer in the alpha S1-casein promoter is associated with abrupt shutdown of alpha S1-casein synthesis during acute mastitis. J. Mol. Endocrinol. 37:463-477. 